\title{
Research Article \\ Effect of Heating Mode and Copper Content on the Densification of W-Cu Alloys
}

\author{
Avijit Mondal, ${ }^{1}$ Anish Upadhyaya, ${ }^{2}$ and Dinesh Agrawal $^{3}$ \\ ${ }^{1}$ NTPC Energy Technology Research Alliance (NETRA), NTPC Ltd., E-III, Echotech-2, Greater Noida 201308, India \\ ${ }^{2}$ Department of Materials Science and Engineering, Indian Institute of Technology, Kanpur 208016, India \\ ${ }^{3}$ Materials Research Institute, The Pennsylvania State University, University Park, PA 16802, USA
}

Correspondence should be addressed to Avijit Mondal; avijit.mondal@gmail.com

Received 18 June 2013; Accepted 13 July 2013

Academic Editors: D. Das and Y. Ge

Copyright (C) 2013 Avijit Mondal et al. This is an open access article distributed under the Creative Commons Attribution License, which permits unrestricted use, distribution, and reproduction in any medium, provided the original work is properly cited.

\begin{abstract}
This study investigates the effect of heating mode on the sintering of tungsten-copper alloys containing up to $30 \mathrm{wt} . \% \mathrm{Cu}$. The sinterability of the W-Cu system consolidated in a $2.45 \mathrm{GHz}$ multimode microwave furnace has been critically compared with that processed in a radiatively heated (conventional) furnace. The as-pressed $\mathrm{W}$-Cu alloys can be readily sintered in microwave furnace with substantial (sixfold) reduction in the processing time. As compared to conventional sintering, microwave processing results in greater densification, more homogenous distribution of the binder phase, and smaller tungsten grain size. The densification in compacts increases with increasing $\mathrm{Cu}$ content. For all compositions, the electrical conductivity and hardness of microwave sintered $\mathrm{W}$-Cu alloys are higher than those of their conventionally sintered counterparts. This study investigates the effect of heating mode on the sintering of tungsten-copper alloys containing up to $30 \mathrm{wt} . \% \mathrm{Cu}$. The $\mathrm{W}$-Cu alloys were sintered in a $2.45 \mathrm{GHz}$ microwave furnace with substantial (sixfold) reduction in the processing time. As compared to conventional sintering, microwave processing results in greater densification, more homogenous distribution of the binder phase, and smaller tungsten grain size. This results in higher electrical conductivity and hardness of the microwave sintered $\mathrm{W}-\mathrm{Cu}$ alloys.
\end{abstract}

\section{Introduction}

Tungsten-copper alloys are widely used for a range of applications, such as electrical contact materials, thermalmanagement devices, and in ordnance applications [1-3]. On account of the refractoriness of the major phase $\left(\mathrm{W}_{\text {m.p. }}\right.$ : $3420^{\circ} \mathrm{C}$ ), these alloys are usually processed through liquid phase sintering [4]. Due to lack of solubility between W and $\mathrm{Cu}$, it is rather difficult to attain full densification in this system. For ensuring complete densification through liquid phase sintering, sufficient amount of melt and its homogeneous distribution are required [5]. Unfortunately, due to the density difference between the constituents, it is rather difficult to ensure $\mathrm{Cu}$ homogeneity. Thus, the $\mathrm{W}$ and $\mathrm{Cu}$ powders are often comilled, which, in turn, results in contamination from the milling media and results in subsequent degradation of property, such as conductivity [6]. Alternatively, $\mathrm{Cu}$ coating over the tungsten has shown to enhance densification during sintering [7]. However, such a technique is not economically viable for upscaling. Another approach for ensuring densification in the $\mathrm{W}-\mathrm{Cu}$ system is through the addition of transition metal additives that activate the sintering kinetics [8-10]. Such activators though remain segregated at the grain boundaries and thereby result in poor mechanical properties [11]. Consequently, most of the efforts are in consolidation of $\mathrm{W}-\mathrm{Cu}$ alloys through the use of ultrafine constituent powders [12]. Such powders are prone to contamination and therefore require careful handling. Most importantly, when processed through a conventionally adopted technique, the compacts from these powders undergo significant microstructural coarsening. It is therefore well recognized that a faster sintering cycle would restrict microstructural coarsening. However, because sintering is a diffusion-driven process, the effect of high heating rate on the densification response is not that straightforward [13]. Furthermore, most conventional sintering furnaces are 
resistance heated and the heat transfer is limited by radiation and conduction. Hence, to ensure uniformity of temperature distribution, the samples are usually heated at a slower rate and for longer times.

In the recent years, on account of the interaction of microwaves with the particulate material, microwave sintering has been widely used for consolidating a range of materials [14]. Till very recently, the application of microwaves was restricted to ceramics and cermets [15]. However, Roy et al. [16] demonstrated that particulate metals too can effectively interact with microwaves and get heated up. This has opened the possibility for consolidating a range of particulate metals and their alloys through microwaves sintering [17]. So far, for the metallic systems, microwave sintering has been applied either for pure metals or for multicomponents systems which have mutual interaction, such as $\mathrm{Fe}-\mathrm{Cu}, \mathrm{Cu}-\mathrm{Sn}$, and $\mathrm{W}$ $\mathrm{Ni}-\mathrm{Fe}$ alloys [18-24]. This study evaluates the feasibility of microwave sintering of $\mathrm{W}-\mathrm{Cu}$ system where the constituents are chemically noninteractive.

\section{Experimental Section}

For the current study, the sintering of $\mathrm{W}-\mathrm{Cu}$ particulate compacts having 10, 20, and $30 \mathrm{wt} . \%$ copper was investigated. The starting powder in as-mixed condition was supplied by NEI Corporation, Somerset, NJ, USA. The tungsten powder size was $70 \mathrm{~nm}$. The as-received powders were uniaxially compacted in a $50 \mathrm{~T}$ hydraulic press (model: CTM-50, supplier: FIE, Ichalkaranji, India) equipped with a floating die. To facilitate compaction, zinc stearate was used as diewall lubricant. Cylindrical compacts having $16 \mathrm{~mm}$ diameter and $8 \mathrm{~mm}$ height were pressed at $200 \mathrm{MPa}$. To take into account the variability of the density of the compacts due to the variation in the composition, the as-pressed (green) and the sintered densities were normalized with respect to the theoretical density which was calculated using the inverse rule of mixture. The green density for all the three compositions was nearly the same and varied 50 to $53 \%$ with the theoretical density.

The as-pressed compacts were sintered using both a radiatively heated (conventional) as well as a $2.45 \mathrm{GHz}$ multimode microwave furnaces. The former was carried in a $\mathrm{MoSi}_{2}$-heated horizontal tubular furnace (model: OKAY 70T, supplier: Bysakh Inc., Kolkata, India) at a constant heating rate of $5^{\circ} \mathrm{C} / \mathrm{min}$. To ensure uniform temperature distribution during heating, intermittent isothermal hold for $30 \mathrm{~min}$ was provided at $500^{\circ} \mathrm{C}$ and $900^{\circ} \mathrm{C}$. For microwave sintering, a $6 \mathrm{~kW}$ microwave furnace (model: RC/20SE, supplier: Amana Radarange) was employed. Further details of the microwave sintering unit are provided elsewhere [20, 21]. All W-Cu compacts were sintered at $1200^{\circ} \mathrm{C}$ in hydrogen atmosphere with dew point $-35^{\circ} \mathrm{C}$. At the sintering temperature, the compacts were kept isothermally for $30 \mathrm{~min}$.

The density of the sintered compacts was evaluated both through dimensional measurements as well as Archimedes' density measurements. To take into account the effect of the initial as-pressed density variation, the compact sinterability

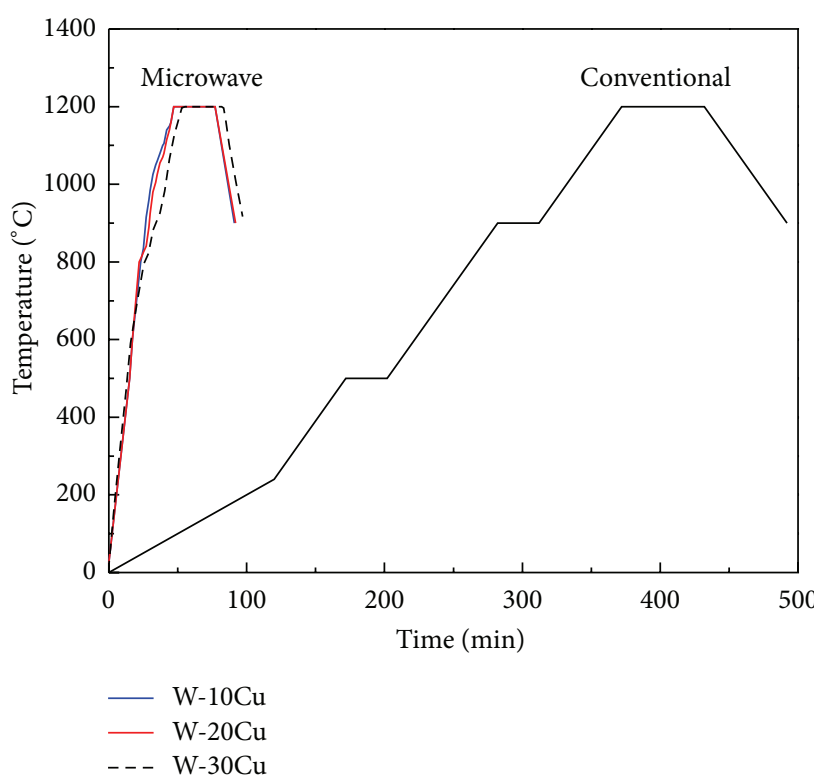

Figure 1: Comparison of heating profile of conventionally and microwave sintered $\mathrm{W}-\mathrm{Cu}$ alloys.

was also expressed in terms of a normalized, dimensionless densification parameter which is expressed as follows:

$$
\begin{aligned}
& \text { densification parameter } \\
& =\frac{(\text { sintered density }- \text { green density })}{\text { (theoretical density }- \text { green density })} .
\end{aligned}
$$

The samples of sintered $\mathrm{W}-\mathrm{Cu}$ alloys were prepared for microstructural investigation using standard metallographic practices. The samples were wet-polished in a manual polisher (model: Lunn Major, supplier: Struers, Denmark) using a series of $6 \mu \mathrm{m}, 3 \mu \mathrm{m}$, and $1 \mu \mathrm{m}$ diamond pastes, which was followed by cloth-polishing using an $0.04 \mu \mathrm{m}$ colloidal silica suspension. The microstructural observations were done using a scanning electron microscope (model: Quanta, supplier: FEI, The Netherlands) both in secondary as well as back-scattered imaging modes.

The bulk hardness of the conventional and microwave sintered $\mathrm{W}-\mathrm{Cu}$ alloys was assessed using a Vickers hardness tester (model: V100-C1, supplier: Leco, Japan) under $50 \mathrm{~N}$ load. To take into account the variability, for each sample, on an average, ten hardness indentations were taken randomly across the cross-section. The electrical conductivity of the sintered W-Cu alloys was evaluated using a digital conductivity meter (model: 757, supplier: TechnoFour, Pune, India).

\section{Results and Discussion}

Figure 1 compares the thermal profiles of the $\mathrm{W}$-Cu compacts consolidated in a conventional and microwave furnace. It is interesting to note that all compacts $(\mathrm{W}-10 \mathrm{Cu}, \mathrm{W}-20 \mathrm{Cu}$, and $\mathrm{W}-30 \mathrm{Cu}$ ) exhibit very strong coupling with microwaves and undergo very rapid heating. As compared to conventional 


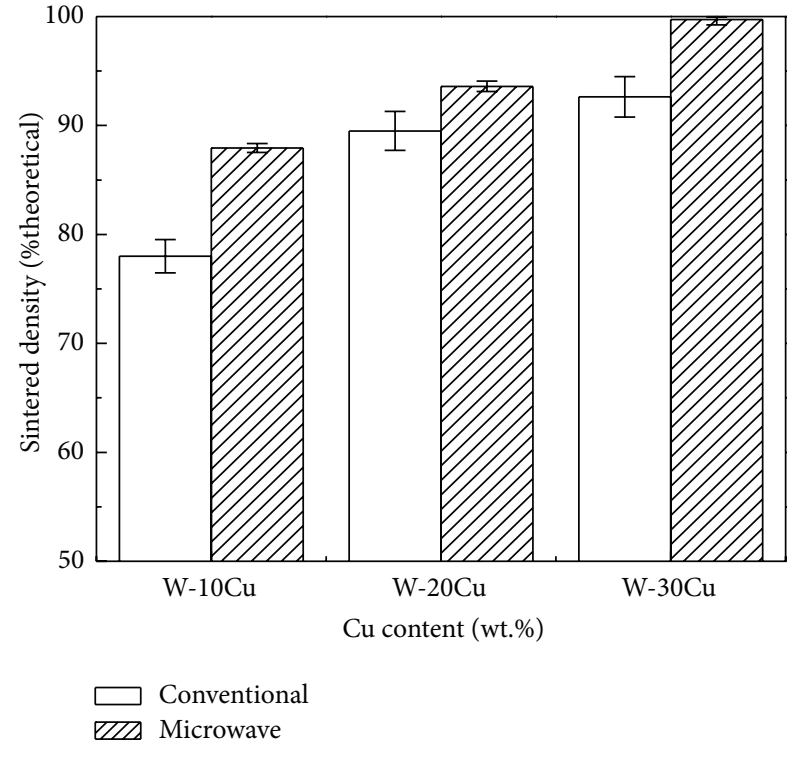

(a)

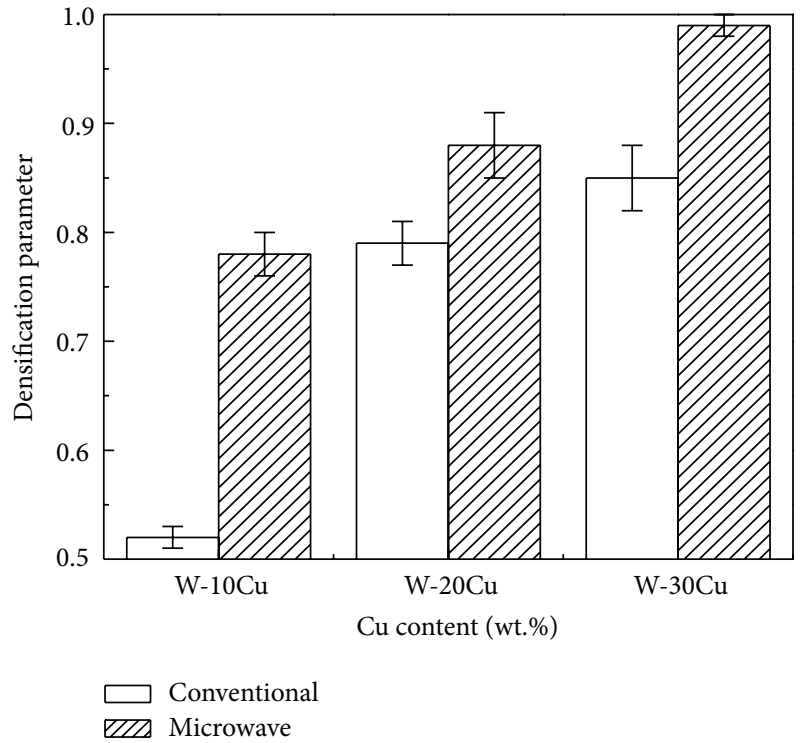

(b)

FIGURE 2: Effect of heating mode on the (a) sintered density and (b) densification parameter of W-Cu alloys containing varying amounts of $\mathrm{Cu}$. All compacts were sintered at $1200^{\circ} \mathrm{C}$.

sintering, microwave heating results in about more than sixfold decrease in the heating time. For conventional sintering, to ensure uniform homogenous heat transfer during heating and prevent thermal shock to the furnace assembly (tube and heating elements), the heating rate was restricted to $5^{\circ} \mathrm{C} / \mathrm{min}$. In comparison, because of the direct coupling of the microwaves with the powder, an overall high heating rate of about $35^{\circ} \mathrm{C} / \mathrm{min}$ was achieved. From Figure 1, it is evident that $\mathrm{W}-\mathrm{Cu}$ compacts can be consolidated in microwave furnace in significantly $(\sim 85 \%)$ lower time that those achieved in a conventional furnace. Mishra et al. [25] have modeled the microwave heating of metals and have elucidated its mechanism in metallic system as mainly joule heating. Usually, for conductive materials, such as metals, the interaction with the microwaves is restricted at the surface and results in eddy currents. This depth of penetration in metals, also known as skin-depth $(\delta)$, is defined as the distance into the material at which the incident power drops to $1 / \mathrm{e}(36.8 \%)$ of the surface value. This skin depth is indirectly proportional to the conductivity of the metals and increases with temperatures. Usually, for most common metallic systems, the skin depth varies in the range of 0.5 to $20 \mu \mathrm{m}$. By corollary, therefore, microwaves will interact volumetrically if the metallic system is in particulate form and contains porosity [26]. For W and $\mathrm{Cu}$, the skin depth varies between $2.5-6 \mu \mathrm{m}$ and $1.75-$ $2.25 \mu \mathrm{m}$, respectively. For tungsten, the initial particle sizes are much smaller as compared to the skin depth, hence it is reasonable to assume that all the tungsten powders get homogenously and volumetrically heated up. The $\mathrm{W}$ $\mathrm{Cu}$ powder due to its poor compressibility and had up to $50 \%$ porosity in the green state. This coupling with the small powder size ensures good interaction of the compact with the microwaves. Elsewhere, other researchers too have reported similar interaction of microwaves with tungsten-based alloys [24, 27-29].

Figure 2(a) compares the effect of $\mathrm{Cu}$ content and the heating mode on the sintered density of the W-Cu compacts. The corresponding densification parameters are summarized in Figure 2(b). From Figure 2, it is interesting to note that the densification of the $\mathrm{W}$-Cu alloys is enhanced with increasing copper content. It can also be inferred that, irrespective of the copper content, the density of microwave sintered compacts is higher than that achieved through conventional sintering. This underscores the efficacy of microwaves processing not only from the viewpoint of sintering time compression but also in densification enhancement standpoint as well. The role of increasing copper content on the densification can be attributed to the greater capillary stresses induced grain rearrangement [30]. During conventional sintering, however, prior to $\mathrm{Cu}$ melt formation, substantial solid-state densification also occurs which results in W-W particle bonding which results in formation of a skeletal structure [31, 32]. In most multiphase systems, the occurrence of such structure is a common occurrence $[33,34]$. However, upon melt formation, the liquid chemically dissolves the interparticle bonds and disintegrates the skeletal structure. In W-Cu system, owing to the insolubility of $\mathrm{W}$ in copper [35], the $\mathrm{Cu}$ melt does not chemically dissolve the W-W interparticle neck formed during solid-state sintering. In addition to poor solubility, the $\mathrm{W}$-Cu has a high dihedral angle $\left(\sim 90^{\circ}\right)[30,36]$. The dihedral angle can be expressed as a balance of the interfacial $\mathrm{W}-\mathrm{Cu}$ melt and W-W energy as well as geometrically in terms of the interparticle $\mathrm{W}-\mathrm{W}$ neck size $(X)$ to the $\mathrm{W}$-grain size $\left(G_{\mathrm{W}}\right)$ ratio as follows [37]:

$$
\phi=2 \cos ^{-1}\left(\frac{\gamma_{\mathrm{WW}}}{\gamma_{\mathrm{W}-\mathrm{Cu}}}\right)=2 \sin ^{-1}\left(\frac{X}{G_{\mathrm{W}}}\right) .
$$


SEM micrograph

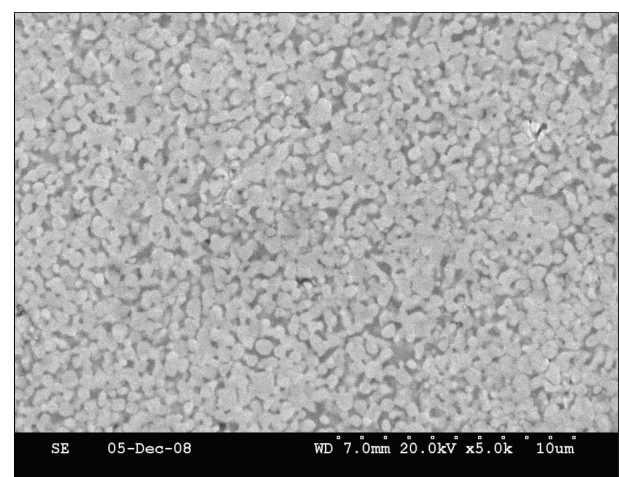

Conventional

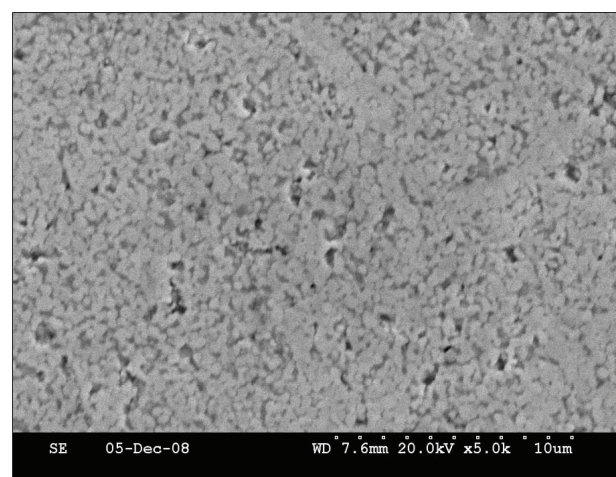

Microwave

(a)

SEM micrograph

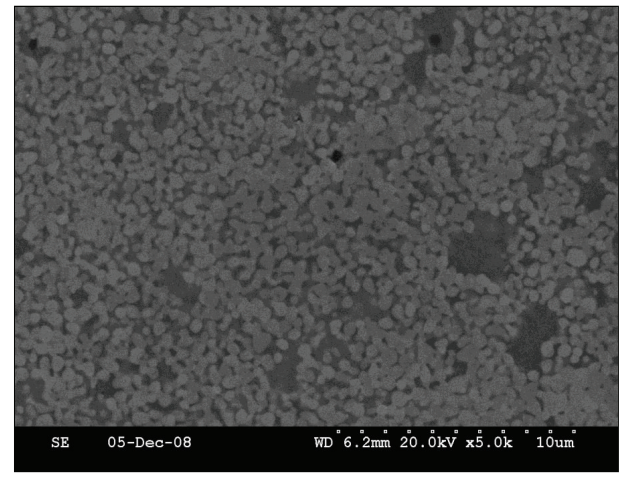

Conventional

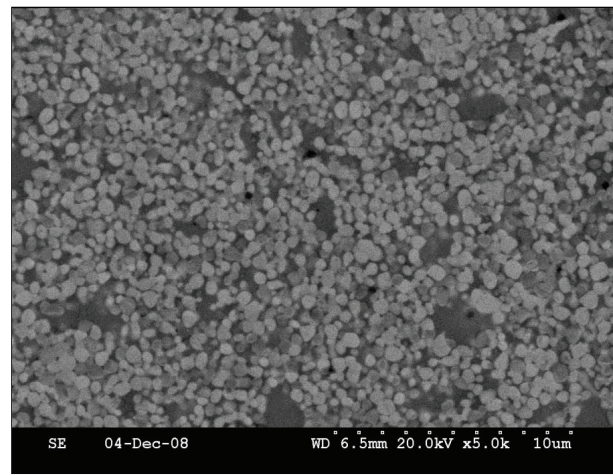

Microwave

(b)

SEM micrograph

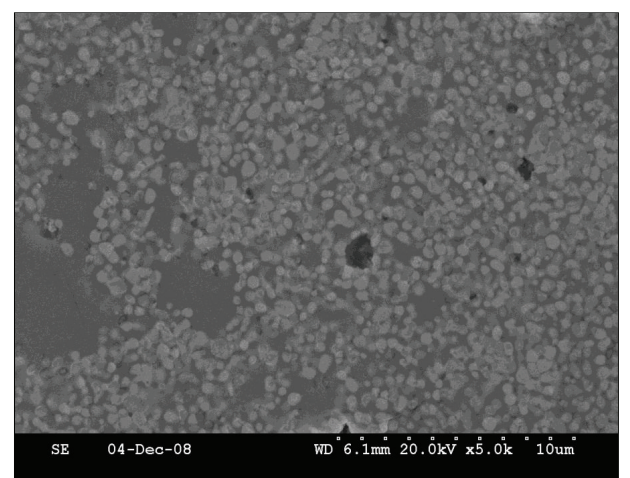

Conventional

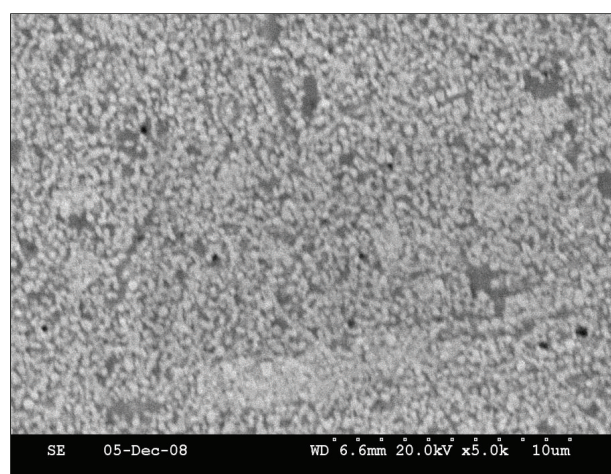

Microwave

(c)

FIGURE 3: SEM photomicrographs of (a) W-10Cu, (b) W-20Cu, and (c) W-30Cu alloys consolidated in a radiatively heated (conventional) and microwave furnaces.

In the $\mathrm{W}-\mathrm{Cu}$ system, the $\mathrm{W}-\mathrm{W}$ interfacial energy is relatively low $\left(2.79 \mathrm{~J} / \mathrm{m}^{2}\right)[38]$; this entails that the interparticle tungsten bonds that form through solid-state sintering are energetically favoured and therefore stable. Thus, on account of both poor intersolubility as well as high dihedral angles, the $\mathrm{W}-\mathrm{Cu}$ system is fundamentally not predisposed for densification due to capillary-induced rearrangement. To circumvent this problem, it is essential that the W-W bond formation prior to melting is restricted. The rapid heating in microwaves helps in achieving this. Thus, it is not surprising that, as compared to conventional heating, microwave sintering results in higher densification. Elsewhere also, 
SEM micrograph

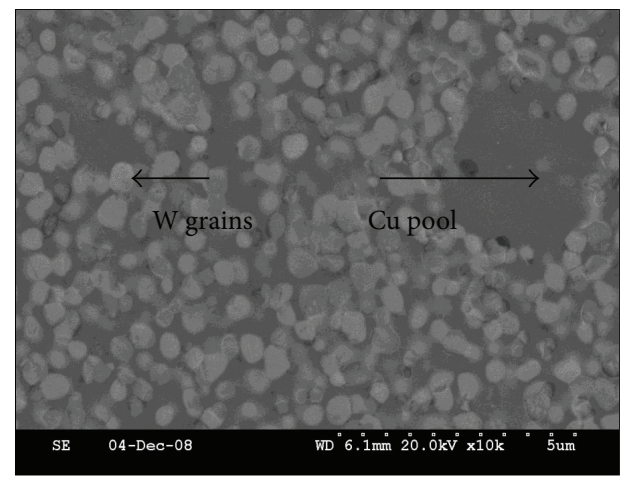

Conventional

(a)

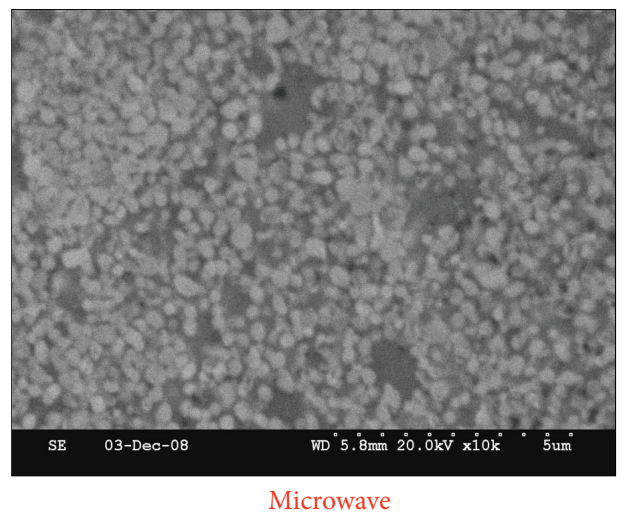

(b)

FIGURE 4: Microstructure of W-30Cu alloys sintered at $1200^{\circ} \mathrm{C}$ in (a) conventional and (b) microwave furnaces.

TABLE 1: Effect of Cu content and heating mode on the grain size, bulk hardness, and electrical conductivity of sintered W-Cu alloys.

\begin{tabular}{lcccc}
\hline Composition (in wt.\%) & Heating mode & Grain Size $(\mathrm{nm})$ & ${\text { Electrical Conductivity }\left(\% \text { IACS}^{*}\right.}$ & Hardness $\left(\mathrm{HV}_{5}\right)$ \\
\hline \multirow{2}{*}{ W-10Cu } & CON & $511 \pm 91$ & $16.0 \pm 0.5$ & $224 \pm 19$ \\
& MW & $362 \pm 104$ & $21.2 \pm 0.3$ & $248 \pm 12$ \\
\hline \multirow{2}{*}{ W-20Cu } & CON & $496 \pm 108$ & $32.6 \pm 0.2$ & $280 \pm 16$ \\
& MW & $403 \pm 105$ & $35.2 \pm 0.5$ & $349 \pm 19$ \\
\multirow{2}{*}{ W-30Cu } & CON & $499 \pm 75$ & $40.0 \pm 0.3$ & $258 \pm 8$ \\
& MW & $302 \pm 63$ & $43.1 \pm 0.7$ & $322 \pm 9$ \\
\hline
\end{tabular}

${ }^{*} \mathrm{CON}$ : conventional; MW: microwave.

researchers $[13,38,39]$ have proposed that slow heating rates are detrimental to rearrangement. However, in conventional resistance heated furnace where the heat transfer mode is predominantly radiative and convective, high heating rates are not readily and economically feasible. Microwave consolidation therefore offers a viable alternative to process $\mathrm{W}-\mathrm{Cu}$ alloys through liquid phase sintering.

Figures 3(a) to 3(c) compare distribution of the binder $(\mathrm{Cu})$ phase in the microstructures of conventionally and microwave sintered $\mathrm{W}-\mathrm{Cu}$ alloys with varying $\mathrm{Cu}$ content. Figures 4(a) and 4(b) compare microstructures (at higher magnification) of liquid phase sintered W-30Cu alloys consolidated in a conventional and microwave furnace, respectively. From Figures 3 and 4, it is evident, that in conventional sintering, copper is more inhomogeneously distributed. Moreover, there is evidence of binder pools which is indicative of poor rearrangement of the bonded skeletal structure that results in densification during liquid phase sintering occurring through pore-filling effect [40]. In a very recent report, Luo et al. [28] also made similar observations. However, their assessment was qualitative and the reason for this was not clearly elaborated. Table 1 summarizes the $\mathrm{W}$ grain sizes measured in the sintered compacts. For both sintering modes, the tungsten grain size reduces as the copper content increases. Similar observations were also reported by
Upadhyaya and German [30] and Mondal et al. [29, 41] on liquid phase sintered $\mathrm{W}-\mathrm{Ni}$ alloys containing $\mathrm{Fe}$ and $\mathrm{Cu}$. However, unlike $\mathrm{W}-\mathrm{Ni}-\mathrm{Fe}$ and $\mathrm{W}-\mathrm{Ni}-\mathrm{Cu}$ systems, due to lack of $\mathrm{W}$ solubility in $\mathrm{Cu}$, solution reprecipitation is not expected to contribute to the tungsten grain coarsening [42]. For the W$\mathrm{Cu}$ system, the grain growth primarily occurs through coalescence for which W-W particle contact is a prerequisite. A higher $\mathrm{Cu}$ volume fraction in the alloys reduces the tungsten contiguity in the structure and thereby results in less coarsening [43]. In case of microwave sintering, besides the less time available for microstructural coarsening, a more uniform melt distribution also contributes towards restricting the grain growth by further reducing the interparticle contacts.

Table 1 also compares the effect of heating mode and the $\mathrm{Cu}$ content on the tungsten grain size, electrical conductivity, and the hardness. As expected, a Cu content in general results in an increase in the electrical conductivity. However, it has an opposing effect on the compact hardness. It is rather interesting to note that, as compared to conventional sintering, the microwave sintered compacts have higher electrical conductivity and greater hardness. This can be correlated to a sintered density, more uniform binder distribution, and a smaller tungsten grain size achieved in the $\mathrm{W}-\mathrm{Cu}$ alloys consolidated in microwave furnace. 


\section{Conclusions}

In summary, this study shows that the $\mathrm{W}-\mathrm{Cu}$ alloys with varying $\mathrm{Cu}$ content can be successfully consolidated through microwave sintering. As compared to conventional sintering, the $\mathrm{W}$-Cu alloys were consolidated in microwaves with about $85 \%$ reduction in the overall processing time. Irrespective of the $\mathrm{Cu}$ content, microwave sintered compacts had higher densification and a more uniform microstructure with lower tungsten grain size. Consequently, the electrical conductivity and the bulk hardness of $\mathrm{W}-\mathrm{Cu}$ sintered alloys using microwaves were higher than those of their counterparts processed through conventional (radiatively heated) furnace.

\section{Acknowledgments}

The authors thank NEI Corporation, Somerset, NJ, USA, for supplying the powder used for this investigation. The financial support from the Indo-US Science and Technology Forum (IUSSTF), New Delhi, for this study is gratefully acknowledged.

\section{References}

[1] A. Upadhyaya, "Processing strategy for consolidating tungsten heavy alloys for ordnance applications," Materials Chemistry and Physics, vol. 67, no. 1-3, pp. 101-110, 2001.

[2] A. Upadhyaya, "Processing strategy for consolidating tungsten heavy alloys for ordnance and thermal-management applications," Transactions of the Indian Institute of Metals, vol. 55, no. 1-2, pp. 51-69, 2002.

[3] R. M. German, K. F. Hens, and J. L. Johnson, "Powder metallurgy processing of thermal management materials for microelectronic applications," International Journal of Powder Metallurgy, vol. 30, no. 2, pp. 205-215, 1994.

[4] A. Belhadjhamida and R. M. German, "Tungsten and tungsten alloys by powder metallurgy: a status review," in Tungsten and Tungsten Alloys Recent Advances, A. Crowson and E. S. Chen, Eds., pp. 3-20, TMS, Warrendale, Pa, USA, 1991.

[5] J. L. Johnson, J. J. Brezovsky, and R. M. German, "Effect of liquid content on distortion and rearrangement densification of liquid-phase-sintered W-Cu," Metallurgical and Materials Transactions A, vol. 36, no. 6, pp. 1557-1565, 2005.

[6] J.-C. Kim, S.-S. Ryu, Y. D. Kim, and I.-H. Moon, "Densification behavior of mechanically alloyed W-Cu composite powders by the double rearrangement process," Scripta Materialia, vol. 39, no. 6, pp. 669-676, 1998.

[7] A. Upadhyaya and C. Ghosh, "Effect of coating and activators on sintering of W-Cu alloys," Powder Metallurgy Progress, vol. 2, no. 2, pp. 98-110, 2002.

[8] J. L. Johnson and R. M. German, "A theory of activated liquid phase sintering and its application to the W-Cu system," in Proceedings of the International Conference \& Exhibition on Powder Metallurgy \& Particulate Materials, vol. 3 of Advances in Powder Metallurgy and Particulate Materials, pp. 35-46, Metal Powder Industries Federation, June 1992.

[9] D.-G. Kim, G.-S. Kim, M.-J. Suk, S.-T. Oh, and Y. D. Kim, "Effect of heating rate on microstructural homogeneity of sintered $\mathrm{W}-15 \mathrm{wt} \% \mathrm{Cu}$ nanocomposite fabricated from $\mathrm{W}-\mathrm{CuO}$ powder mixture," Scripta Materialia, vol. 51, no. 7, pp. 677-681, 2004.
[10] V. Gauthier, F. Robaut, A. Upadhyaya, and C. H. Allibert, "Effect of $\mathrm{Fe}$ on the constitution of $\mathrm{Cu}-\mathrm{W}$ alloys at $1200^{\circ} \mathrm{C}$," Journal of Alloys and Compounds, vol. 361, no. 1-2, pp. 222-226, 2003.

[11] J. L. Johnson and R. M. German, "Factors affecting the thermal conductivity of W-Cu composites," in Proceedings of the International Conference \& Exhibition on Powder Metallurgy \& Particulate Materials, vol. 4 of Advances in Powder Metallurgy and Particulate Materials, pp. 201-213, Metal Powder Industries Federation, May 1993.

[12] J. L. Johnson, J. J. Brezovsky, and R. M. German, "Effects of tungsten particle size and copper content on densification of liquid-phase-sintered W-Cu," Metallurgical and Materials Transactions A, vol. 36, no. 10, pp. 2807-2814, 2005.

[13] R. M. German and S. Farooq, "An update on the theory of liquid phase sintering," in Sintering'87, S. Sōmiya, M. Shimada, M. Yoshimura, and R. Watanabe, Eds., vol. 1, pp. 459-464, Elsevier Science, New York, NY, USA, 1988.

[14] M. Gupta and W. L. E. Wong, Microwaves and Metals, John Wiley \& Sons, Singapore, 2007.

[15] K. Rödiger, K. Dreyer, T. Gerdes, and M. Willert-Porada, "Microwave sintering of hardmetals," International Journal of Refractory Metals and Hard Materials, vol. 16, no. 4-6, pp. 409416, 1998.

[16] R. Roy, D. Agrawal, J. Cheng, and S. Gedevanishvili, "Full sintering of powdered-metal bodies in a microwave field," Nature, vol. 399, pp. 668-670, 1999.

[17] K. Saitou, "Microwave sintering of iron, cobalt, nickel, copper and stainless steel powders," Scripta Materialia, vol. 54, no. 5, pp. 875-879, 2006.

[18] R. M. Anklekar, D. K. Agrawal, and R. Roy, "Microwave sintering and mechanical properties of PM copper steel," Powder Metallurgy, vol. 44, no. 4, pp. 355-362, 2001.

[19] M. Gupta and W. L. E. Wong, "Enhancing overall mechanical performance of metallic materials using two-directional microwave assisted rapid sintering," Scripta Materialia, vol. 52, no. 6, pp. 479-483, 2005.

[20] S. S. Panda, V. Singh, A. Upadhyaya, and D. Agrawal, "Sintering response of austenitic (316L) and ferritic (434L) stainless steel consolidated in conventional and microwave furnaces," Scripta Materialia, vol. 54, no. 12, pp. 2179-2183, 2006.

[21] S. S. Panda, V. Singh, A. Upadhyaya, and D. Agrawal, "Effect of conventional and microwave sintering on the properties of yttria alumina garnet-dispersed austenitic stainless steel," Metallurgical and Materials Transactions A, vol. 37, no. 7, pp. 2253-2264, 2006.

[22] C. Padmavathi, A. Upadhyaya, and D. Agrawal, "Corrosion behavior of microwave-sintered austenitic stainless steel composites," Scripta Materialia, vol. 57, no. 7, pp. 651-654, 2007.

[23] A. Upadhyaya and G. Sethi, "Effect of heating mode on the densification and microstructural homogenization response of premixed bronze," Scripta Materialia, vol. 56, no. 6, pp. 469-472, 2007.

[24] A. Upadhyaya, S. K. Tiwari, and P. Mishra, "Microwave sintering of W-Ni-Fe alloy," Scripta Materialia, vol. 56, no. 1, pp. 5-8, 2007.

[25] P. Mishra, G. Sethi, and A. Upadhyaya, "Modeling of microwave heating of particulate metals," Metallurgical and Materials Transactions B, vol. 37, no. 5, pp. 839-845, 2006.

[26] A. Mondal, D. Agrawal, and A. Upadhyaya, "Microwave heating of pure copper powder with varying particle size and porosity," The Journal of Microwave Power and Electromagnetic Energy, vol. 43, no. 1, pp. 5-10, 2009. 
[27] G. Prabhu, A. Chakraborty, and B. Sarma, "Microwave sintering of tungsten," International Journal of Refractory Metals and Hard Materials, vol. 27, no. 3, pp. 545-548, 2009.

[28] S. D. Luo, J. H. Yi, Y. L. Guo, Y. D. Peng, L. Y. Li, and J. M. Ran, "Microwave sintering W-Cu composites: analyses of densification and microstructural homogenization," Journal of Alloys and Compounds, vol. 473, no. 1-2, pp. L5-L9, 2009.

[29] A. Mondal, A. Upadhyaya, and D. Agrawal, "Microwave sintering of refractory metals/alloys: W, Mo, Re, W-Cu, W-Ni$\mathrm{Cu}$ and W-Ni-Fe alloys," The Journal of Microwave Power and Electromagnetic Energy, vol. 44, no. 1, pp. 28-44, 2010.

[30] A. Upadhyaya and R. M. German, "Densification and dilation of sintered W-CU alloys," International Journal of Powder Metallurgy, vol. 34, no. 2, pp. 43-55, 1998.

[31] J. L. Johnson and R. M. German, "Solid-state contributions to densification during liquid-phase sintering," Metallurgical and Materials Transactions B, vol. 27, no. 6, pp. 901-909, 1996.

[32] V. V. Panichkina and N. I. Filipov, "Structure formation processes in the sintering of disperse copper-tungsten pseudoalloys," Science of Sintering, vol. 26, pp. 269-275, 1994.

[33] G. S. Upadhyaya, Sintered Metallic and Ceramic Materials, John Wiley \& Sons, New York, NY, USA, 2000.

[34] A. P. Savitskii, Liquid Phase Sintering of the Systems with Interacting Components, Russian Academy of Sciences, Tomsk, Russia, 1993.

[35] H. Okamoto, P. R. Subramaniam, and L. Kacprzak, Binary Phase Diagrams, vol. 2, American Society for Microbiology, Materials Park, Ohio, USA, 2nd edition, 1990.

[36] A. Upadhyaya and R. M. German, "Shape distortion in liquidphase-sintered tungsten heavy alloys," Metallurgical and Materials Transactions A, vol. 29, no. 10, pp. 2631-2638, 1998.

[37] R. M. German, P. Suri, and S. J. Park, "Review: liquid phase sintering," Journal of Materials Science, vol. 44, no. 1, pp. 1-39, 2009.

[38] B. D. Storozh and P. S. Kislyi, "Sintering of tungsten-alumina cermets in the presence of a liquid phase," Soviet Powder Metallurgy and Metal Ceramics, vol. 13, no. 9, pp. 712-716, 1974.

[39] R. Bollina and R. M. German, "Heating rate effects on microstructural properties of liquid phase sintered tungsten heavy alloys," International Journal of Refractory Metals and Hard Materials, vol. 22, no. 2-3, pp. 117-127, 2004.

[40] S.-M. Lee and S.-J. L. Kang, "Theoretical analysis of liquid-phase sintering: pore filling theory," Acta Materialia, vol. 46, no. 9, pp. 3191-3202, 1998.

[41] A. Mondal, A. Upadhyaya, and D. Agrawal, "Microwave sintering of W-18Cu and W-7Ni-3Cu alloys," The Journal of Microwave Power and Electromagnetic Energy, vol. 43, no. 1, pp. 11-16, 2009.

[42] W. J. Huppmann, "The elementary mechanisms of liquid phase sintering: II. solution-reprecipitation," Zeitschrift fuer Metallkunde, vol. 70, pp. 792-797, 1979.

[43] S.-C. Yang, S. S. Mani, and R. M. German, "The effect of contiguity on growth kinetics in liquid-phase sintering," Journal of Metals, vol. 42, no. 4, pp. 16-19, 1990. 

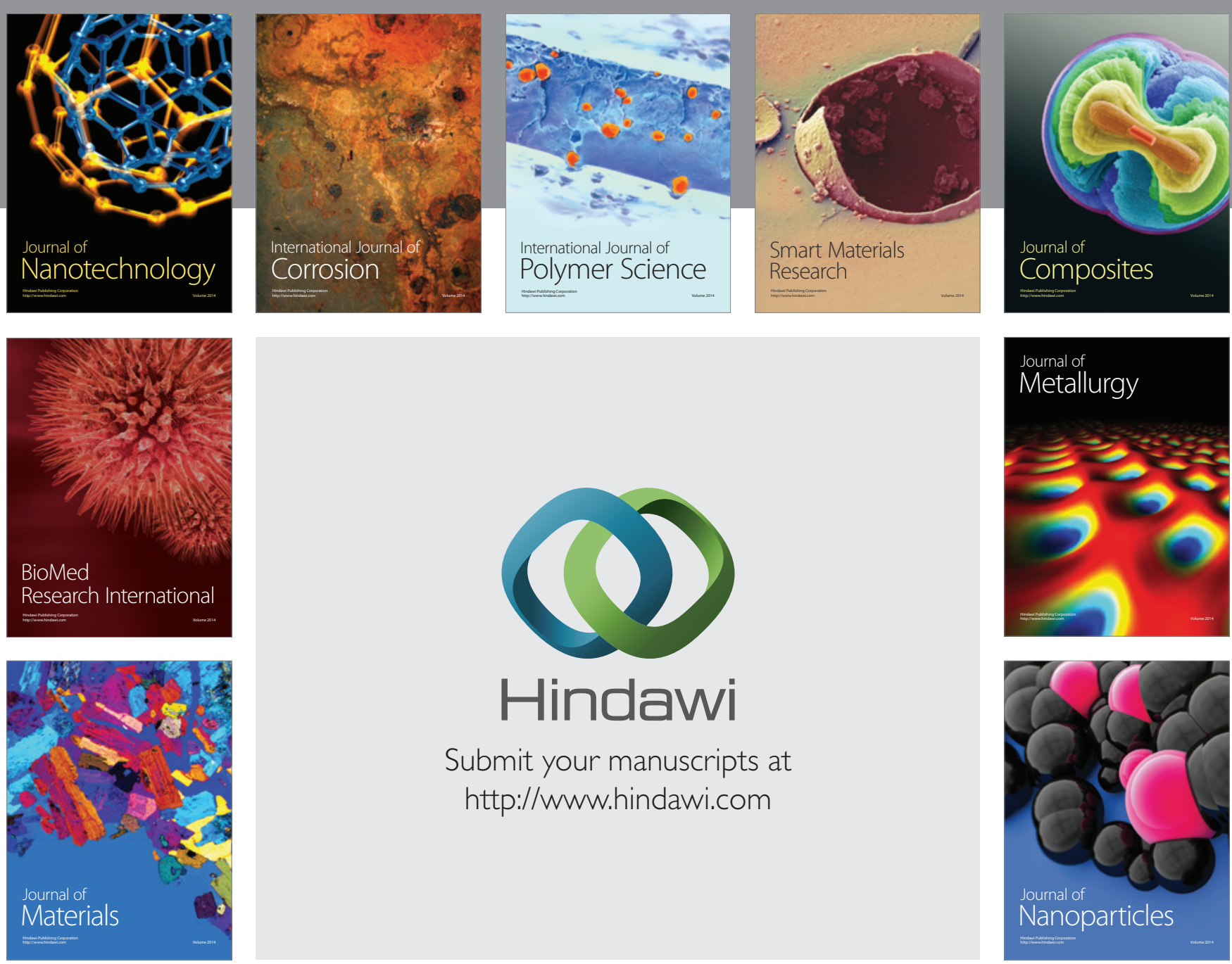

Submit your manuscripts at http://www.hindawi.com
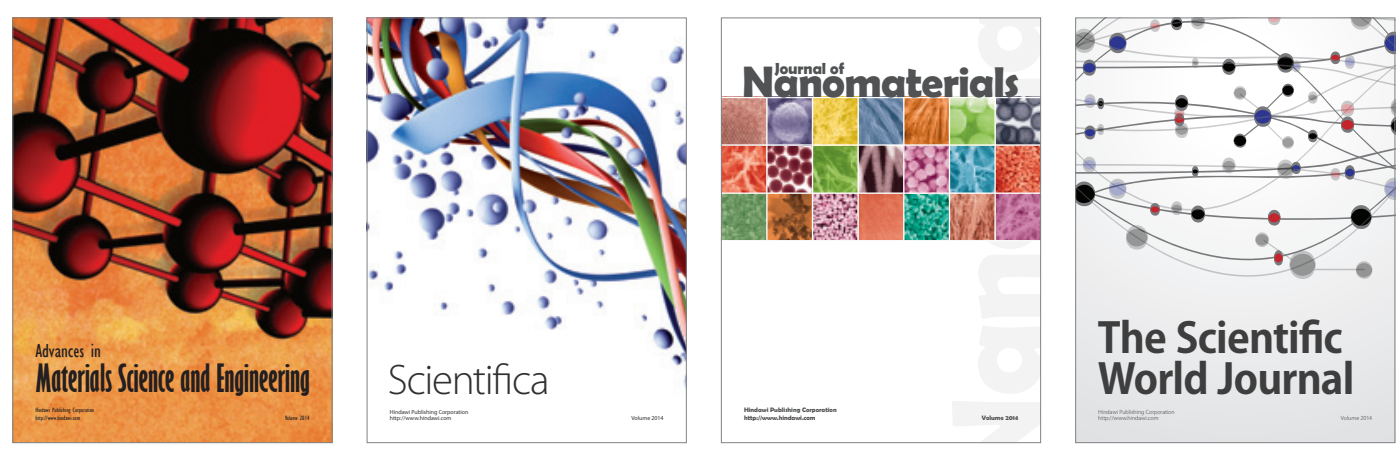

\section{The Scientific World Journal}
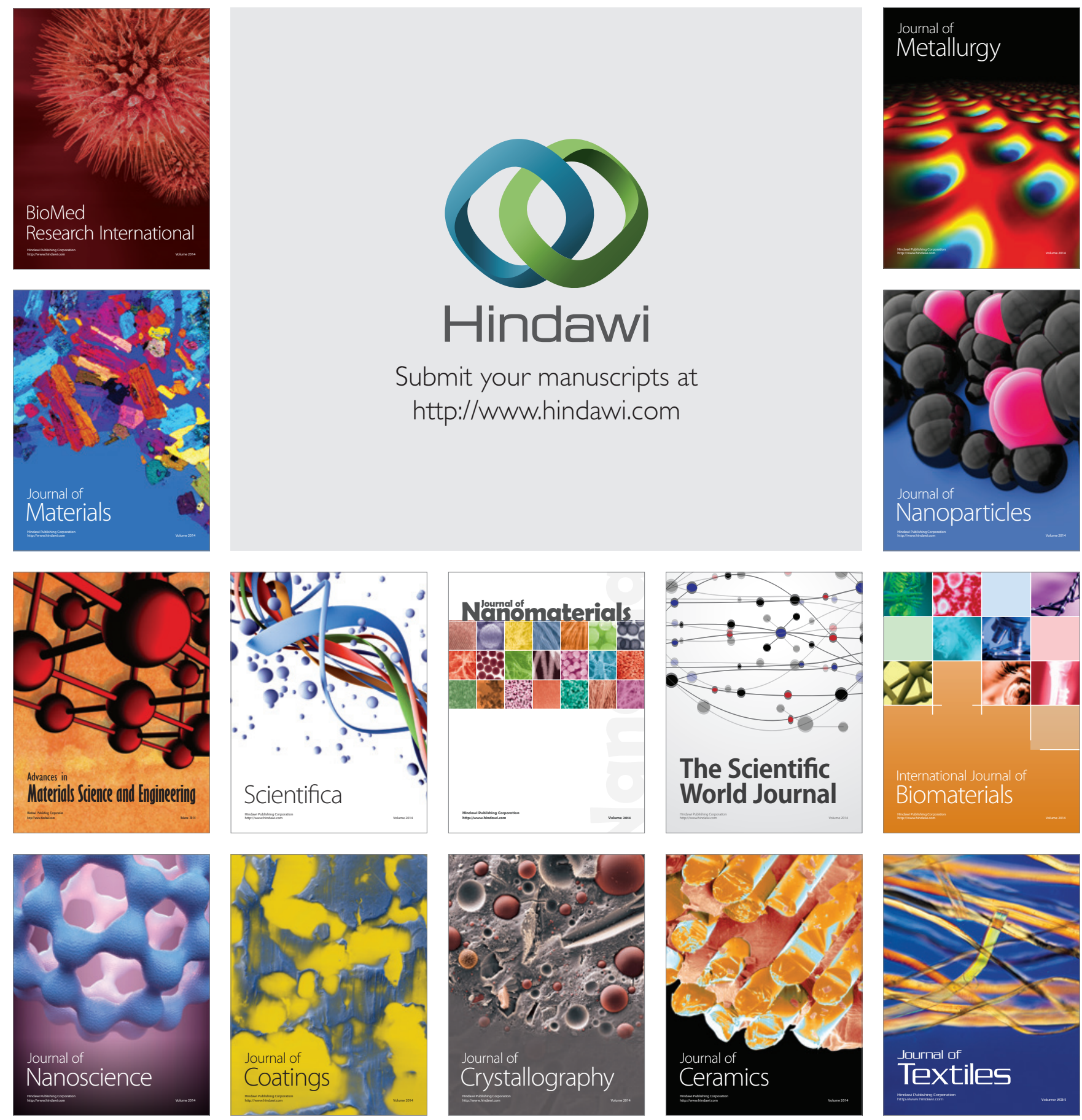